\title{
Increased writing activity in neurological conditions: a review and clinical study
}

\author{
P van Vugt, P Paquier, L Kees, P Cras
}

\begin{abstract}
Increased writing activity in a 70 year old, right handed man presenting with a history of alcohol misuse and maturity onset diabetes is reported. Brain CT disclosed corticosubcortical atrophy and ${ }^{99 \mathrm{~m} T c-}$ HMPAO SPECT disclosed severe bilateral frontal hypoperfusion more prominent on the right. The patient's neuropsychological symptomatology consisted of severe (verbal) aspontaneity, intermittent utilisation behaviour, and pronounced increased writing activity, which mainly consisted of a perseverative, micrographic written reproduction of visually or verbally perceived language fragments. Several neurological causes of increased writing activity and the equivocal terminology met in the medical literature are reviewed. A distinction between hypergraphia and automatic writing behaviour is proposed. It is concluded that our patient's increased writing activity may be characterised as automatic writing behaviour.
\end{abstract}

(F Neurol Neurosurg Psychiatry 1996;61:510-514)

Keywords: frontal lobe; hypergraphia; compulsive writing

Unit of

Neurolinguistics,

University of Antwerp

(UIA), Belgium

$P$ van Vugt

L Kees

Department of ENT

Surgery, University of

Antwerp (UIA) and

Department of

Neurology, University

Hospital Erasme

(ULB), Belgium

P Paquier

Department of

Neurology (Born-

Bunge Foundation),

University of Antwerp

(UIA), Belgium

P Cras

Correspondence to

Dr P van Vugt, Unit of

Neurolinguistics, CBL-UIA

Universiteitsplein 1, B-2610

Wilrijk, Belgium.

Received 22 November 1995

and in final revised form

3 July 1996

Accepted 4 July 1996 Increased writing activity in mental illness is a well accepted topic of interest. ${ }^{12}$ On the other hand, abnormal writing behaviour resulting from neurological disorder is seldom reported. Probably the best known example is the ictal ${ }^{3}$ or interictal increased writing activity seen in some patients with temporal lobe epilepsy. ${ }^{1456}$ However, its frequency and specificity in temporal lobe epilepsy4 have been questioned: increased writing activity has also been described in mentally retarded patients (epileptic and non-epileptic) ${ }^{7}$ and in patients with brain tumours, ${ }^{89}$ cerebral strokes, ${ }^{10}$ multiple sclerosis, ${ }^{11}$ or frontal lobe dementia. ${ }^{12}$

In the past, increased writing activity has been referred to as hypergraphia, ${ }^{1}$ echographia, ${ }^{13}$ graphomania, ${ }^{8}$ anosognosic graphomimia, ${ }^{14}$ graphorrhée, ${ }^{15}$ and phonographie. ${ }^{16}$ Although diagnostic criteria have been proposed, ${ }^{14}{ }^{17}$ a comparative study of case reports shows that one term may cover different types of behaviour and that similar increased writing activities have been labelled differently. We would like to clear up the terminological confusion in the literature on increased writing activity by reporting another patient and by differentiating automatic writing behaviour from hypergraphia.

\section{Case report}

A 70 year old right handed man with a long history of alcohol and tobacco misuse and a previous medical history of well controlled non-insulin dependent diabetes mellitus was admitted after a fall causing a left orbitomaxillar fracture. He had been drinking several beers a day for many years and had shown progressive memory disturbances during the year before admission. Relatives reported dyspraxic behaviour, decreased verbal output, and two fugue episodes. Clinical examination on admission showed a frail, apathetic old man who was disoriented in time and space. His liver was slightly enlarged. There was no tremor and no asterixis. He displayed bilateral grasping, and there was a clear bilateral palmomental reflex. During his stay in hospital the patient remained aspontaneous. Only rarely did he respond, with one or two words, adequately answering the question. He walked with a wide base and there was bilateral reduced diadochokinesia. However, there was no ataxia nor dysmetria.

Laboratory tests showed slightly raised ammonia (up to $66 \mathrm{mg} / 100 \mathrm{ml}$ ). Hepatic enzymes were normal, except for gGT which was slightly raised. Chest radiography, urine, thyroid function, serology (for Treponema pallidum, HIV), uric acid, lipids, vitamin B12, and CSF tests were negative or normal. His EEG showed theta waves in the occipital lobes. Brain CT disclosed pronounced, generalised corticosubcortical atrophy and ventriculomegaly more prominent on the right. As normal pressure hydrocephalus was suspected Omnipaque ${ }^{\circledR}$ was injected intrathecally. The resorption of CSF was normal. ${ }^{99 m} \mathrm{Tc}-$ HMPAO SPECT showed severe frontal hypoperfusion, more pronounced on the right (fig 1).

The mini mental state examination ${ }^{22}$ was nication, but the patient scored $11 / 30$ at his difficult to evaluate due to the lack of commu- 


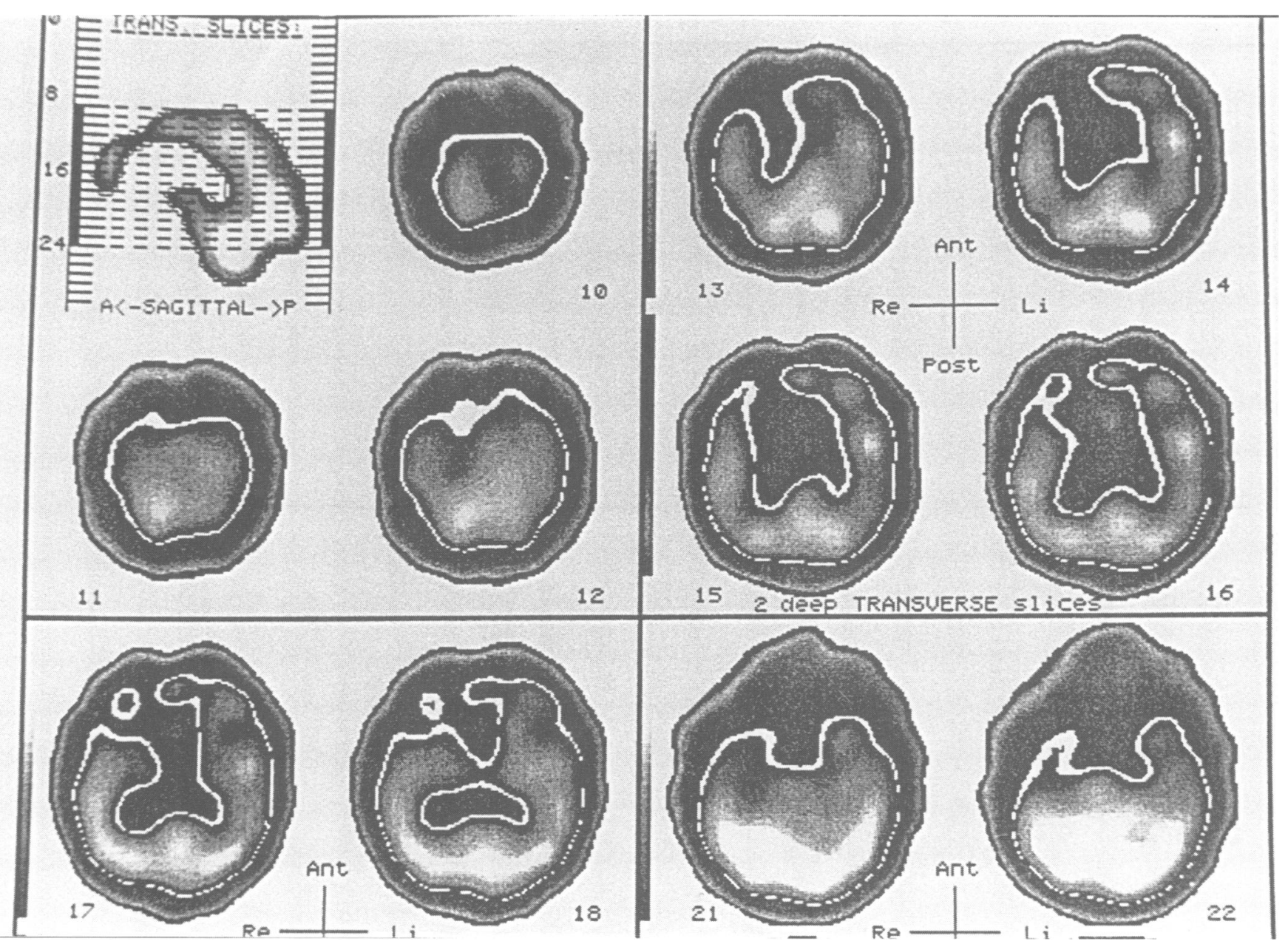

Figure $1{ }^{99 m}$ Tc-HMPAO SPECT images show severe frontal hypoperfusion, more pronounced on the right.

best. Psychiatric examination showed some loss of decorum. The patient did not confabulate. There was no obsessive compulsive personality disorder and during clinical bedside examination no obsessional traits were found. On the ward he displayed a mild form of utilisation behaviour and a pronounced increased writing activity.

During an observation period of five weeks, the patient produced 22925 written words. The writing was micrographic but legible (fig 2). Generally, the patient copied whatever he set his eyes on: a newspaper headline, the instructions on the television set, the trade mark on his pencil. He went on copying until the end of the page or until another visual stimulus caught his eye (table). The copying was rather careless: punctuation, numbers, and abbreviations were not always respected, conjunctions were often added (and ... and ... and), prepositions were substituted. The intrusion of neologisms suggested lexical wandering (for example, de eeuwige achtervelden, the happy backing grounds). As he became more distracted during the act of writing, he would insert questions asked to him or a sentence overheard in a conversation. As a result, the text sometimes became very awkward and difficult to understand.

The patient's writing activity was closely monitored during weeks 2 and 3. The nursing staff made sure that the patient only had a notebook at his disposal and every morning care was taken to replace the ballpoint pen used the day before by a differently coloured one. To observe the patient's communicative reaction when confronted with unexpected written stimuli, we surreptitiously inserted questions about his youth, his family, the hospital food, etc in the otherwise blank notebook. Instructions related to writing as well as geometric figures alternated with these questions, as we wanted to assess the patient's ability to adapt his behavioural pattern and the degree to which the imitation was servile (table).

The differences in ink disclosed that during the observation period the patient wrote three to four pages a day. He tended to fill all the space available on the pages, and would often return to previous pages to fill up the margins horizontally and vertically. Except for one instance of shadow copying, small as well as large geometric patterns were disregarded and simply covered with text. Horizontal lines did not influence the writing activity, whereas vertical lines seem to have been perceived and respected as margins, or at least as an element organising writing space. Usually, questions and instructions were copied several times. Occasionally a semantically related one word or one syntagma response was formulated and repeated over and over again. More than once, the copied instruction was personalised-for example, "You must not write here" became "I must not write here". 


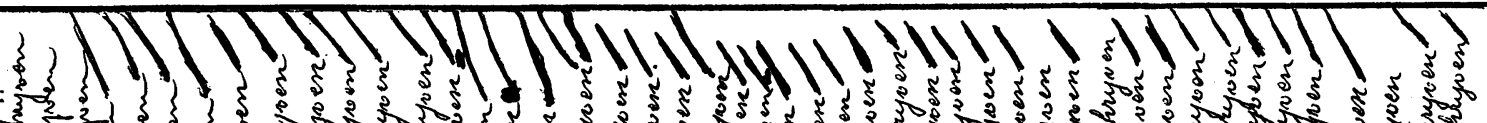

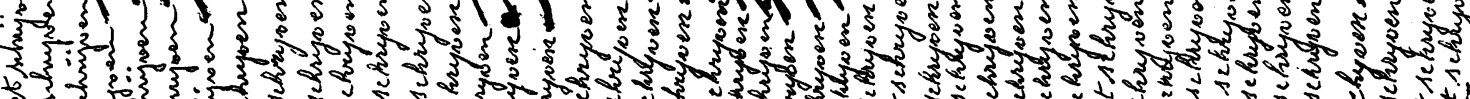

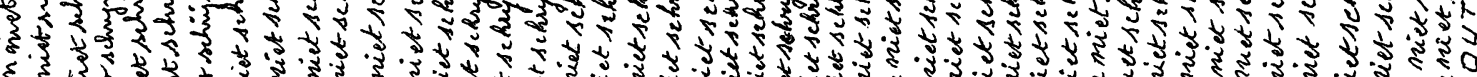 30,

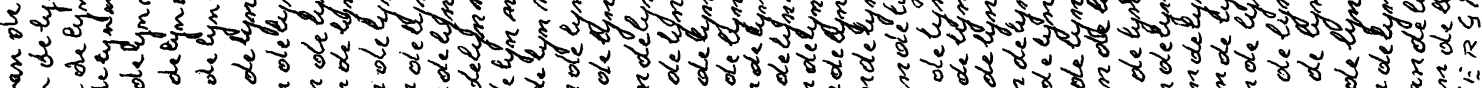 ई3

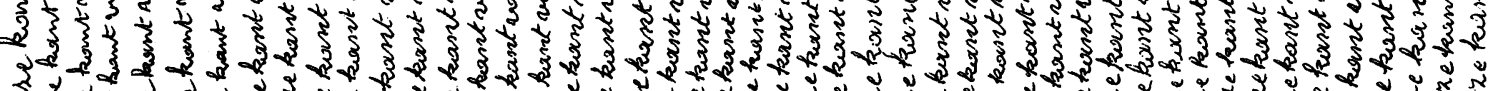 2.

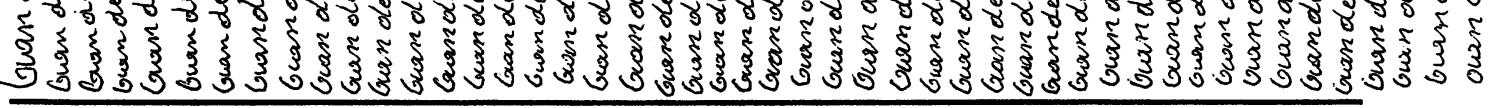

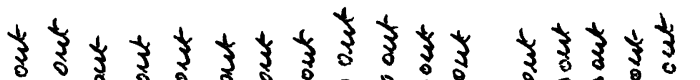

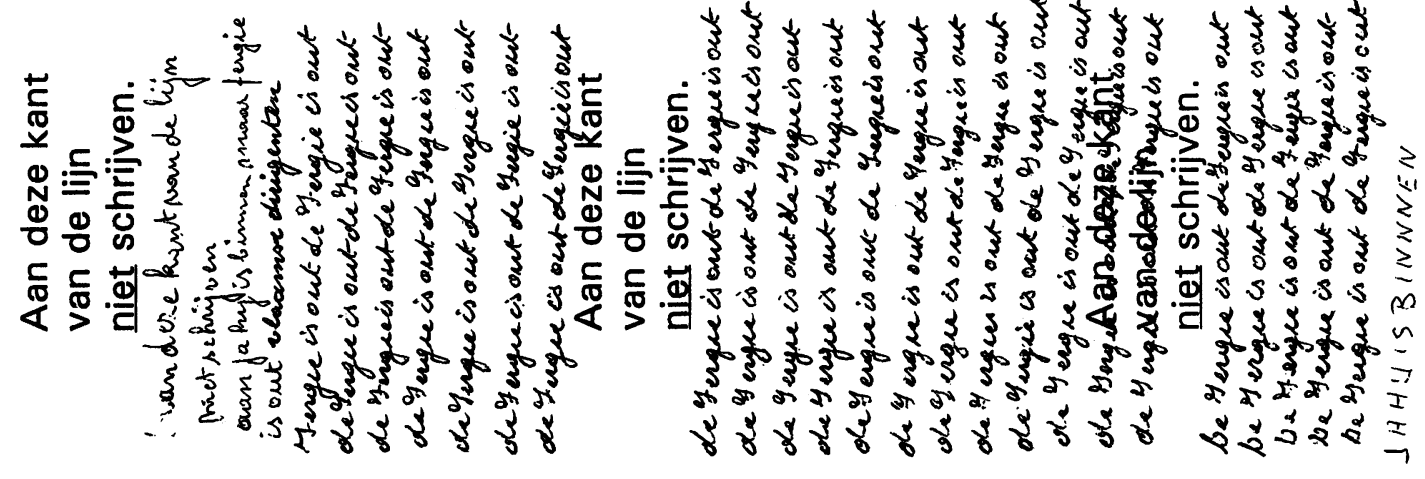

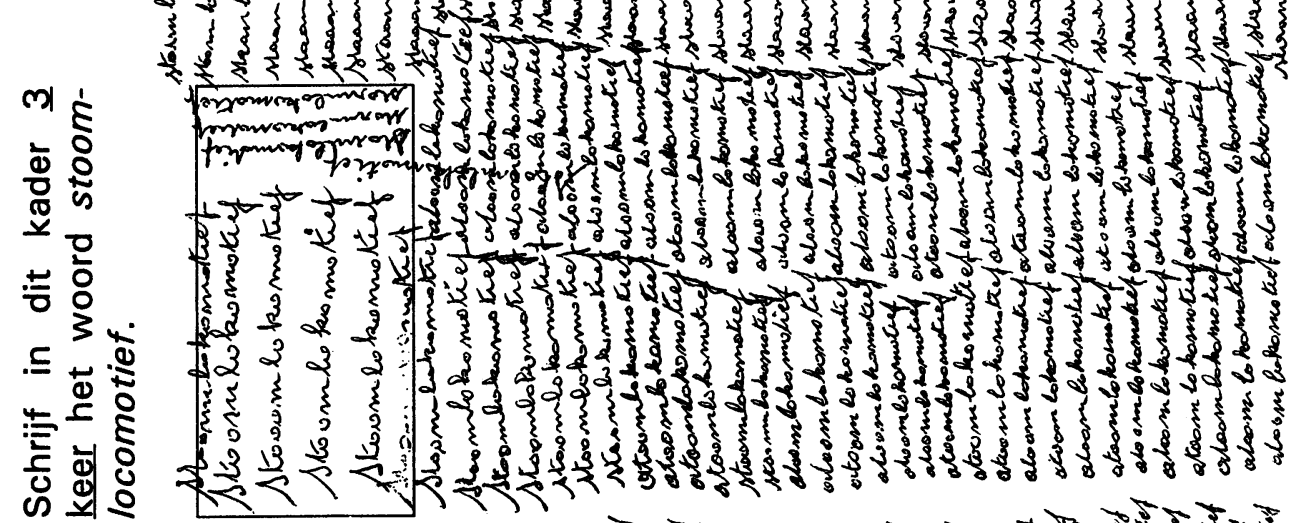

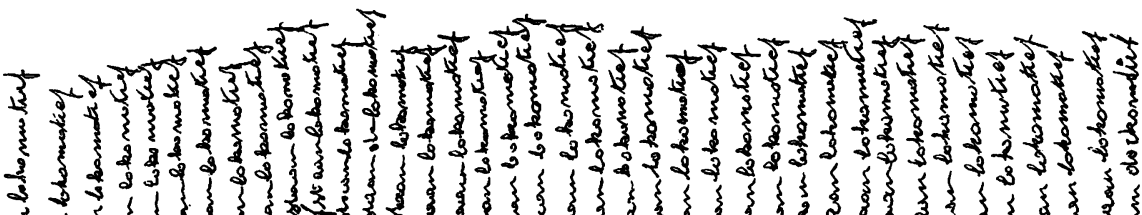

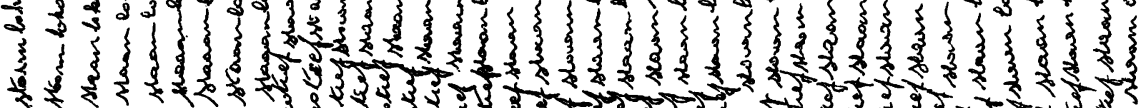
3.

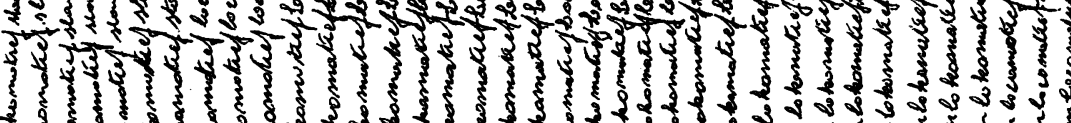

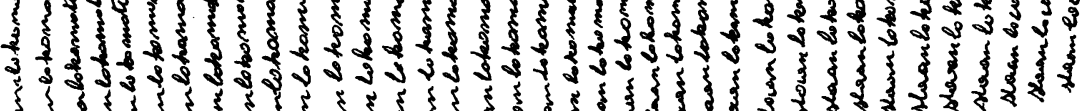

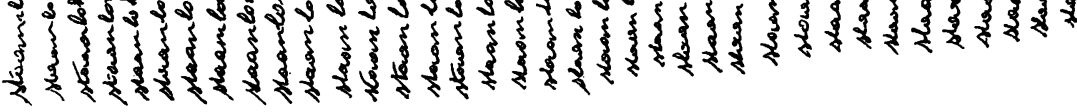


Some examples of instructions and stimuli randomly inserted in a blank DIN A5 notebook, and description of the patient's graphic response

\begin{tabular}{|c|c|c|}
\hline Instruction or stimulus & Spatial display & Patient's response \\
\hline $\begin{array}{l}\text { Write the word steam engine } \\
\text { three times in the box }\end{array}$ & See fig $2 \mathrm{~A}$ & $\begin{array}{l}\text { The word is initially copied four times. Later on, the } \\
\text { patient wrote the word another five times in the box. } \\
\text { Finally, the page is covered with the word. }\end{array}$ \\
\hline $\begin{array}{l}\text { Copy below the following } \\
\text { sentence once }\end{array}$ & $\begin{array}{l}\text { Printed at } 130 \mathrm{~mm} \\
\text { from the top }\end{array}$ & $\begin{array}{l}\text { The sentence is copied once. The next day we found } \\
\text { out that the same sentence had been used to cover the } \\
\text { entire page as well as the next two pages. }\end{array}$ \\
\hline $\begin{array}{l}\text { Do not write on this side of } \\
\text { the line }\end{array}$ & $\begin{array}{l}\text { Printed in a } 60 \mathrm{~mm} \text { wide } \\
\text { margin, see fig } 2 \mathrm{~B}\end{array}$ & $\begin{array}{l}\text { The ban is copied on the right side of the line; afterwards, } \\
\text { the patient fills up the restricted area. }\end{array}$ \\
\hline Do you like the food? & Printed at the page centre & $\begin{array}{l}\text { Unrelated page covering writing, until the question is } \\
\text { reached. Below the question is answered } 64 \text { times: } \\
\text { "Yes, very much". }\end{array}$ \\
\hline Diamond $140 \times 90 \mathrm{~mm}$ & Page centred & $\begin{array}{l}\text { The patient keeps on writing straight across the geometric } \\
\text { figure. }\end{array}$ \\
\hline $\begin{array}{l}\text { Were you on good terms with } \\
\text { your mother? Explain why }\end{array}$ & Printed at the page centre & $\begin{array}{l}\text { The answering starts at the top of the page. "I was on } \\
\text { good terms with my mother }(2 \times) \text { and I will think } \\
\text { about it and I will not mince matters everything is OK } \\
\text { OK love you (illegible) and I will ask Jimmy Frey (a } \\
\text { popular singer) }(4 \times) \text { and I was on good terms with my } \\
\text { mother }(5 \times) \text { and it depended on what father wanted in } \\
\text { my small world mother is still not lost and }(\ldots) \text { ". }\end{array}$ \\
\hline Describe your youth & $\begin{array}{l}\text { Printed at } 30 \mathrm{~mm} \\
\text { from the top }\end{array}$ & $\begin{array}{l}\text { Unrelated text above the instruction, below is written } \\
\text { in a page covering fashion: "my youth was I always the } \\
\text { youth what a world the youth and the youth and I was } \\
\text { always and what a youth (...)". }\end{array}$ \\
\hline Serpentine curve & $\begin{array}{l}\text { Printed at the right } \\
\text { of the page }\end{array}$ & $\begin{array}{l}\text { At first the curve is copied, } 4 \mathrm{~mm} \text { at the left. Afterwards, } \\
\text { text is displayed at the left of both curves. Finally, both } \\
\text { curves are covered with text. }\end{array}$ \\
\hline
\end{tabular}

When the pen was removed while the patient was writing, he kept his meek, gentle, and slightly absent minded physiognomy. There were no signs of anxiety or frustration. However, a very strong grasp reflex made it difficult to take the pen away. When the paper was slightly pulled aside by the examiner during writing, the patient would firmly hold it with his left hand.

The examination of the utilisation behaviour took place in a quiet and almost distracter free observation room. When a nail hammered into a piece of wood was presented together with a nail puller, the patient would extract the nail, despite the examiner's warning not to do so. Similarly, although he had repeatedly been instructed not to touch the objects, the patient could not resist using the pair of scissors in front of him to cut the sheet of paper which had been laid on the table. When a plastic cup and a bottle of motor oil were put in front of the patient, he seized the bottle and started reading the directions for use. There was, however, no attempt to open the bottle or to pour the oil. At other times, however, there was no utilisation reaction. For instance, when given an open envelope containing a visible letter, the patient would not start reading it; he held the envelope until he was asked to give it back. Similarly, the presentation of a nail, a hammer, and a wooden block did not result in hammering the nail into the block. On the contrary, the objects were left untouched. It must be said that, in the few instances of utilisation behaviour, the initiation of the response took a certain time. This was by contrast with the activities related to writing, which had much shorter response latencies. Moreover, the presence of a pen, a pencil, a sharpener, and a ruler always resulted in the prompt initiation of writing, pencil sharpening, line drawing, etc. Whereas the use or manipulation of other objects was seldom repetitive, writing related activities had a continuous aspect and were difficult to interrupt. Verbal or printed orders not to write or to stop writing were dis- regarded. The sharpening of a pencil resembled a psychomotor automatism and a considerable effort was needed to separate the patient's hands.

After a month, the patient's verbal output had slightly improved: he answered questions with one word responses and occasionally uttered short sentences. Written questions and instructions yielded a significantly faster response than their spoken counterparts (eight instructions in an ABBA design: $t=\mathbf{4} \cdot \mathbf{4 1}$, $P=0.003$ ). The increased writing activity was still very prominent and annoyed his room mates, who insisted very strongly that nurses or speech therapists took away the patient's pencil and notebooks.

\section{Discussion}

Our patient's neuropsychological symptomatology consisted of severe (verbal) aspontaneity, intermittent utilisation behaviour, and abnormally increased writing activity, which mainly consisted of a perseverative written reproduction of visually or verbally perceived language fragments. On this basis, as well as in the rather loose semantic coherence of his written production, he closely resembled the patient of Cambier et al. ${ }^{8}$ As in previous reports on increased writing activity in patients with left brain damage, ${ }^{13}$ patients with right brain damage, ${ }^{910}$ and patients with temporal lobe epilepsy with ictal increased writing activity $^{3}$ our patient's writing behaviour was also avolitional, automatic, and mechanical.

A relation between features of increased writing activity and underlying causes or lesion site and side seems to exist in some, but certainly not in all patients. It has been suggested $^{17}$ that conscious and attentive writing is associated with epilepsy, and automatic compulsive writing with stroke, degenerative, or space occupying disease. However, this assumption is thwarted by Joseph's ${ }^{3}$ report of a patient with temporal lobe epilepsy who presented with frequent, sudden onset, non-voli- 
tional writing automatisms. Moreover, some patients with right brain damage reported by Yamadori et al ${ }^{10}$ displayed in their notes the overinclusive style described in patients with temporal lobe epilepsy. To avoid confusion when causal mechanisms are discussed, we would like to redefine some terms in a merely behavioural perspective.

Although it is not always easy to measure the degree of content productivity in repetitive language, ${ }^{1319}$ the communicative intention of the patient's writing may help to distinguish several forms of increased writing activity. Moreover, in patients with temporal lobe epilepsy or right brain damage ${ }^{10}$ a rather thematic repetitiveness is found, whereas in other types of increased writing activity, a formal repetition on syntactic, lexical, or graphemic level is seen. An aspect of continuity parallels this distinction: by contrast with the patients of Pick, ${ }^{13}$ Cambier et al, ${ }^{8}$ and Gil et al ${ }^{14}$ and our patient, the increased writing activity is not constantly present or elicitable either in temporal lobe epilepsy or in stroke patients with right brain damage. Therefore, we propose to call hypergraphia all transient increased writing activity with a non-iterative appearance on syntactic or lexicographemic level. We suggest reserving the term automatic writing behaviour to indicate a permanently present or elicitable, compulsive, iterative, and not necessarily complete written reproduction of visually or orally perceived messages, as is the case in our patient. With respect to the nature of the pressure of writing it is important to pay attention to the patient's behaviour when engaged in writing activity. If a patient shows frustration or anxiety when pen and paper are removed from him while writing, it may be assumed that the increased writing activity is related to an obsessive compulsive disorder. ${ }^{20}$ On the other hand, if deprivation of writing material does not induce such a reaction, a truly compulsive syndrome is less likely to explain the increased writing activity. As far as our aspontaneous patient is concerned, the fact that he tried to immobilise the sheet that was pulled aside by the examiner while he was writing, points to his desire to continue his activity. However, it is doubtful whether such a mild reaction can reasonably be considered an instance of obsessive compulsive behaviour.

Several case reports of automatic writing behaviour suggest or document an involvement of left or right frontal lobe areas using imaging techniques and neurobehavioural descriptions. It seems reasonable to accept automatic writing behaviour as a particular, sometimes isolated, form of utilisation behaviour, in the sense that the inhibitory function of the frontal lobes is suppressed, thus leaving the subject dependent on the slightest stimulus. ${ }^{21}$ With respect to the mechanisms leading to hypergraphia this is less conclusive. We endorse the view of Cambier $e a^{8}$ that in temporal lobe epilepsy the desire to record facts and events might underlie the hypergraphia, as recent investigations have considered hypergraphic behaviour an emotional response in trying to cope with the sometimes frightening memory problems caused by cerebral lesions. ${ }^{22}$

In view of these findings, the following guidelines may be clinically useful. In severe cases of automatic writing behaviour, taking away all writing material might contribute to the psychological comfort of the patient's relatives and room mates. In cases of hypergraphia it seems best to allow the writing activity, as discomfort or an increase of fear is likely to result when the patient is deprived of the means to write.

1 Trimble $M$. Hypergraphia. In: Trimble $M$, Bolwig T, eds. Aspects of epilepsy and psychiatry. London: John Wiley and Sons, 1986,75-87.

2 Ludwig A. Mental illness and creative activity in female writers. Am f Psychiatry 1994;151:1650-6.

3 Joseph A. A hypergraphic syndrome of automatic writing affective disorder, and temporal lobe epilepsy in two patients. $\mathcal{f}$ Clin Psychiatry 1986;47:255-7.

4 Davey $D$, Thompson P. Interictal language functioning in chronic epilepsy. Fournal of Neurolinguistics 1991;6: 381-99.

5 Hermann B, Whitman S, Wyler A, Richey E, Dells J. The neurological, psychosocial and demographic correlates of hypergraphia in patients with epilepsy. $\mathcal{f}$ Neurol Neurosurg Psychiatry 1988;51:203-8.

6 Roberts J, Robertson M, Trimble M. The lateralizing significance of hypergraphia in temporal lobe epilepsy. $f$ nificance of hypergraphia in temporal lobe

7 Jancar J, Kettle L. Hypergraphia and mental handicap. fournal of Mental Deficiency Research 1984;28:151-8.

8 Cambier J, Masson C, Benammou S, Robine B. La graphomanie, activité graphique compulsive manifestation d'un gliome fronto-calleux. Rev Neurol (Paris) 1988 144:158-64.

9 Imamura T, Yamadori A, Tsuburaya K. Hypergraphia associated with a brain tumour of the right cerebral hemisphere. F Neurol Neurosurg Psychiatry 1992;55:25-7.

10 Yamadori A, Mori E, Tabuchi M, Kudo Y, Mitani Y. Hypergraphia: a right hemisphere syndrome. $\mathcal{f}$ Neurol Neurosurg Psychiatry 1986;49:1 160-4.

11 Kanemoto K, Akamatsu T, Itagaki Y, Nishitani H. Early onset multiple sclerosis with hypergraphia and KlüverBucy syndrome: a case report. Neurological Medicine (Tokyo) 1990;32:301-3.

12 Frisoni G, Scuratti A, Bianchetti A, Trabucchi M Hypergraphia and brain damage. F Neurol Neurosurg Psychiatry 1993;56:576-7.

13 Pick A. On the pathology of echographia. Brain 1924;47: 417-29.

14 Gil R, Neau JP, Aubert I, Fabre C, Agbo C, Tantot AM Graphomimie anosognosique: variété particulière d'hypergraphie au cours d'un infarctus sylvien droit. $R e v$ Neurol (Paris) 1995;151:198-201.

15 Manuila A, Manuila L, Nicole M, Lambert H. Dictionnaire français de médecine et de biologie. Paris: Masson, 1970.

16 Bernard C. De l'aphasie. Paris, 1889?.

17 Okamura T, Motomura N, Asaba H, et al. Hypergraphia in temporal lobe epilepsy, compared with stroke of the right cerebral hemisphere. fapanese fournal of Psychiatry and Neurology 1989;43:524-5.

18 Folstein MF, Folstein SE, McHugh PR. Mini-Mental State. F Psychiatr Res 1975;12:189-98.

19 Perkins M. Repetitiveness in language disorders: a new Perkins $M$. Repetitiveness in language disorders: a new
analytical procedure. Clinical Linguistics and Phonetics analytical proced

20 Cooper J. Obsessional illness and personality. In: Russell G, Hersov L, eds. Handbook of psychiatry. Vol 4: the neuroses and personality disorders. Cambridge: Cambridge University Press, 1983,258-74

21 Lhermitte F. Utilization behaviour and its relation to lesions of the frontal lobes. Brain 1983;106:237-55.

22 Okamura T, Fukai M, Yamadori A, Hidari M, Asaba $H$ Sakai T. A clinical study of hypergraphia in epilepsy. $f$ Neurol Neurosurg Psychiatry 1993;56:556-9. 